CARADDE: Jurnal Pengabdian Kepada Masyarakat
$\begin{gathered}\text { https://journal.ilininstitute.com/index.php/caradde } \\ \text { Volume 1 | Nomor 2 | Februari | 2019 } \\ \text { e-ISSN: 2621-7910 dan p-ISSN: 2621-7961 } \\ \text { DOI: } \text { https://doi.org/10.31960/caradde.v1i2.26 }\end{gathered}$

\title{
Kualitas Bibit Durian Unggul Lokal Palopo
}

\author{
Sukriming Sapareng ${ }^{1}$, Muhammad Yusuf Idris, Intisari ${ }^{4}$, Sitti Maryam Yasin ${ }^{3}$, Rosnina ${ }^{5}$
}

Keywords :
Pembibitan;
Teknik Budidaya;
Analisis Kelayakan Usaha;
Aroma
Finansial
Corespondensi Author
${ }^{1}$ Agroteknologi, Universitas Andi
Djemma Palopo
Jl. Mungkasa No. 35 D
Email: miming.mlgke@gmail.com

History Artikel

Received: September-2018;

Reviewed: November-2018

Accepted: Desember-2018

Published: Februari-2019

\begin{abstract}
Abstrak. Budidaya tanaman durian (Durio zibethinus L.) di Indonesia memiliki prospek tinggi karena mempunyai nilai komersial yang tinggi dan permintaan konsumen pada saat musim durian yang cukup tinggi. Selain itu untuk agroindustri, buah durian dapat dijadikan sebagai bahan campuran makanan maupun minuman sehingga mempunyai nilai ekonomis cukup tinggi. Penelitian bertujuan menganalisis usaha pembibitan durian unggul lokal Palopo yang mempunyai citrarasa khas dengan aroma yang lebih ringan. Kendala utama pada pengembangan durian yaitu penyediaan bibit yang berkualitas. Usaha untuk mengatasi hal tersebut dapat dilakukan melalui teknik penyediaan bibit yang baik dan benar dengan cara vegetatif (berasal dari okulasi maupun sambung pucuk). Hasil penelitian analisis kelayakan usaha menunjukkan bahwa pembibitan durian unggul lokal Palopo dinyatakan layak dari sisi finansial. Berdasarkan hasil perhitungan harga pokok produksi minuman bibit diperoleh $R p 2.515,82$. Hasil kelayakan usaha bibit durian diperoleh nilai $N P V=R p 1.345 .334,21$, gross $B / C=1.7244$, net $B / C=3.9214$, dan $I R R=63 \%$.
\end{abstract}

This work is licensed under a Creative Commons Attribution

4.0 International License

\section{PENDAHULUAN}

Buah-buahan merupakan komoditas hortikultura yang mempunyai serapan pasar cukup tinggi. Kondisi ini merupakan prospek yang cukup baik untuk dikembangkan. Salah satu komoditas buah-buahan unggulan bagi Provinsi Sulawesi Selatan adalah komoditas durian. Saat ini durian semakin banyak dilirik orang untuk dikebunkan, buah ini memang layak untuk dikebunkan secara komersial, mengingat permintaan dan harganya yang cukup tinggi dibandingkan dengan buah lainnya. Daya serap pasar terhadap durian sampai dengan dua puluh tahun mendatang diperkirakan cukup baik. Dari perhitungan kasar, potensial pasar durian Indonesia masih mampu menyerap pengembangan sampai 100.000 hektar dengan tingkat produksi 10 ton per hektar. Perhitungan tersebut diambil dengan perkiraan daya serap penduduk Indonesia terhadap durian bias mencapai $5 \mathrm{~kg}$ (1,5 butir) per kapita per tahun (Wiryanta, 2001).

Prospek budidaya durian di Indonesia khususnya di Kota Palopo Sulawesi Selatan cukup menjanjikan karena mempunyai nilai komersial yang tinggi. Hal ini terlihat dari permintaan konsumen pada saat musim durian yang cukup tinggi. Selain itu untuk agroindustri, buah durian dapat dijadikan sebagai bahan campuran makanan maupun minuman sehingga mempunyai nilai 
Caradde: Jurnal Pengabdian Kepada Masyarakat

Vol 1 No 2, Februari 2019

ekonomis cukup tinggi. Durian unggul lokal Palopo mempunyai citrarasa khas dengan aroma yang lebih ringan. Umumnya konsumen menyukai durian dengan aroma yang lebih ringan dan mengandung vitamin yang cukup tinggi (Gorinstein et al., 2011; Belgis et al., 2017). Kendala dalam pengembangan durian salah satunya adalah penyediaan bibit. Usaha untuk mengatasi hal tersebut dapat dilakukan melalui teknik penyediaan bibit yang baik dan benar. Pembibitan dilakukan baik secara generatif (berasal dari biji) maupun vegetatif (berasal dari okulasi maupun sambung pucuk).

Petani atau penangkar yang melakukan usaha pembibitan durian di Kotamadya Palopo Sulawesi Selatan belum mengusahakan dan mengembangkan secara luas dan intensif. Jumlah produksi tidak mampu memenuhi permintaan karena kurangnya supply (penawaran) dari pelaku usahtani pembibitan durian. Jumlah petani/penangkar pembibitan durian hanya 20 orang petani/penangkar. Kurangnya informasi yang mampu menarik perhatian untuk melakukan usaha ini, juga salah satu faktor penyebab minimnya para pelaku usaha pembibitan durian. Hal ini yang menjadi alasan perlu dilakukannya pengabdian dan penelitian yang memberi informasi kepada para petani atau penangkar usaha pembibitan atau bagi para calon investor.

\section{METODE}

\section{Bahan dan Alat}

Bahan yang digunakan dalam penelitian ini yaitu benih durian, polibag ukuran $20 \times 30$ $\mathrm{cm}$, pupuk kandang ayam, tanah lapisan atas (top soil), pasir, sekam padi, Furadan 3G, fungisida Anfush, insektisida Curacron. Alat yang digunakan yaitu karung, cetok, cangkul, timbangan, kayu balok, paranet, ayakan, kamera, computer, cangkul, sprayer, staples, meteran, dan alat tulis menulis.

\section{Metode Pelaksanaan}

Data yang diambil dalam penelitian ini meliputi data primer dan data sekunder. Data primer yaitu teknik budidaya pembibitan (Gambar 1 dan Gambar 2), biaya produksi, jumlah bibit, harga jual, dan teknik pemasaran bibit. Sedangkan data sekunder meliputi kependudukan, iklim, letak geografis, sarana dan prasarana fisik, serta data informasi lainnya yang mendukung.
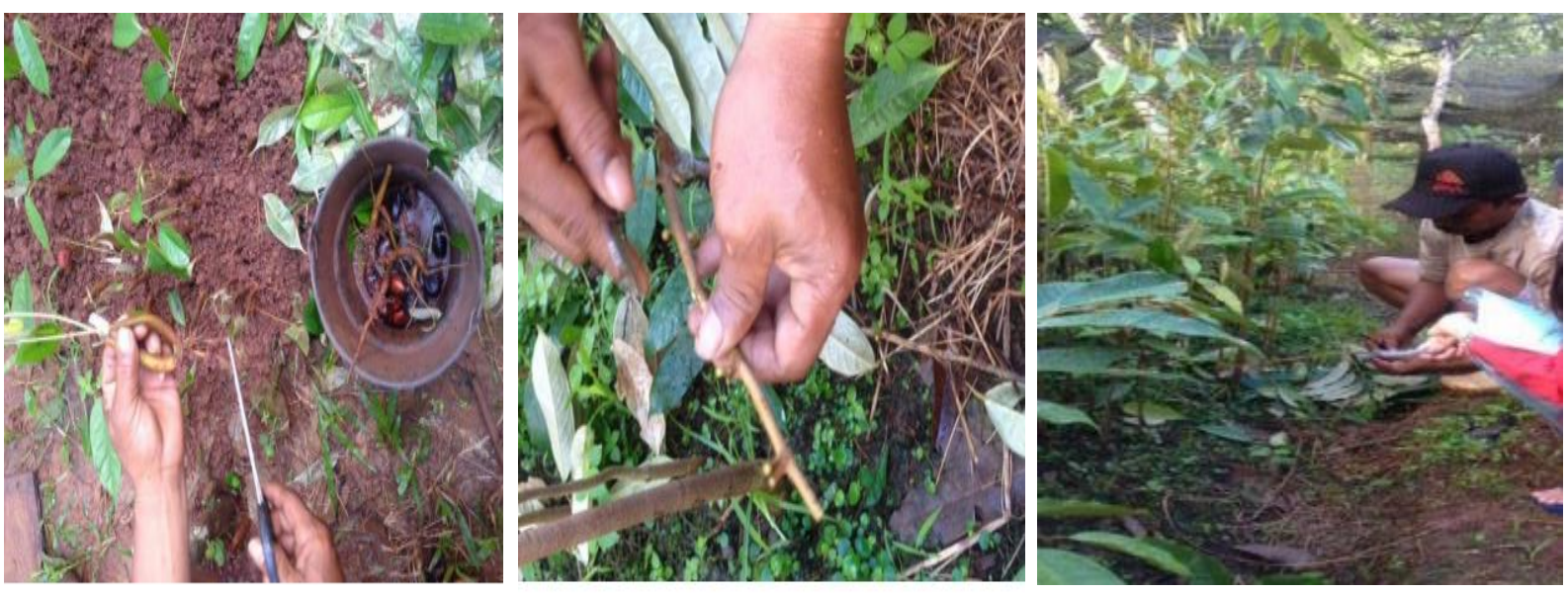

Gambar 1. Bahan dan proses okulasi bibit durian

\section{Analisis Deskriptif}

Analisis deskriptif kualitatif digunakan untuk menjelaskam aspek pemasaran. Analisis ini menjelaskan mengenai pemasaran produk termasuk di dalamnya mengenai karakteristik konsumen, volume pembelian yang dilakukan konsumen serta pembentukan harga. Gambaran mengenai pemasaran dalam penelitian ini di bahas secara deskriptif dengan mengkaji data kualitatif yang diperoleh dalam penelitian. Analisis ini dimaksudkan untuk mendukung hasil yang diperoleh dari analisis finansial sehingga hasil dapat dijelaskan dari sisi usaha mengenai pemasaran produknya. 


\section{Analisis Kelayakan Usaha Berdasarkan}

Kriteria Investasi (Nurmalina et al., 2009)

\section{Net Present Value (NPV)}

$$
N P V=\sum_{t=0 / 1}^{n} \frac{B t}{(1+i)^{t}}-\sum_{t=0 / 1}^{n} \frac{C t}{(1+i)^{t}}
$$

Keterangan: $\mathrm{Bt}=$ manfaat pada tahun $\mathrm{t}, \mathrm{Ct}=$ biaya pada tahun $\mathrm{t}, \mathrm{t}=$ tahun kegiatan bisnis $(\mathrm{t}=0,1,2,3, \ldots, \mathrm{n})$, tahun awal bisa tahun 0 atau tahun 1 tergantung karakteristik bisnisnya, $\mathrm{i}=$ tingkat discount rate (\%). Indikator: jika NPV $>0$ (positif) maka bisnis layak untuk dilaksanakan dan jika NPV $<0$ (negatif) maka bisnis tidak layak untuk dilaksanakan.

\section{Gross Benefit-Cost Ratio}

Gross $B / C=\frac{\sum_{t=0 / 1}^{n} \frac{B t}{(1+i)^{t}}}{\sum_{t=0 / 1}^{n} \frac{C t}{(1+i)^{t}}}$

Keterangan $: \mathrm{Bt}=$ manfaat pada tahun $\mathrm{t}, \mathrm{Ct}=$ biaya pada tahun $\mathrm{t}, \mathrm{t}=$ tahun kegiatan bisnis $(\mathrm{t}=0,1,2,3, \ldots, \mathrm{n})$ tahun awal bisa tahun 0 atau tahun 1 tergantung karakteristik bisnisnya, $\mathrm{I}=$ tingkat discount rate (\%). Indikator :jika gross $\mathrm{B} / \mathrm{C}>1$, maka bisnis layak untuk dilaksanakan, jika gross $\mathrm{B} / \mathrm{C}<1$, maka bisnis tidak layak untuk dilaksanakan.

\section{Net Benefit-Cost Ratio}

Net $B / C=\frac{\sum_{t=\frac{0}{1}(1+i)^{t}}^{n} \frac{B t}{(B t-C t)>0}}{\sum_{t=\frac{0}{1}(1+i)^{t}}^{n} \frac{C t}{(B t-C t)<0}}$

Keterangan: $\mathrm{Bt}=$ manfaat pada tahun $\mathrm{t}, \mathrm{Ct}=$ biaya pada tahun $\mathrm{t}, \mathrm{t}=$ tahun kegiatan bisnis $(\mathrm{t}=0,1,2,3, \ldots, \mathrm{n})$ tahun awal bisa tahun 0 atau tahun 1 tergantung karakteristik bisnisnya, $\mathrm{i}=$ tingkat discount rate (\%). Indikator: jika net $\mathrm{B} / \mathrm{C}>1$ maka bisnis layak untuk dilaksanakan, jika net $\mathrm{B} / \mathrm{C}<1$ maka bisnis tidak layak untuk dilaksanakan.

\section{Internal Rate of Return (IRR)}

$I R R=i_{1}+\frac{N P V 1}{N P V 1-N P V 2} x\left(i_{1}-i_{2}\right)$

Keterangan: $i_{1}=$ discount rate yang menghasilkan NPV positif, $\mathrm{i}_{2}=$ discount rate yang menghasilkan NPV negatif, $\mathrm{NPV}_{1}=$ NPV positif, $\mathrm{NPV}_{2}=\mathrm{NPV}$ negatif. Indikator: sebuah bisnis dikatakan layak apabila IRRnya lebih besar dari oppurtinity cost of capitalnya (DR).

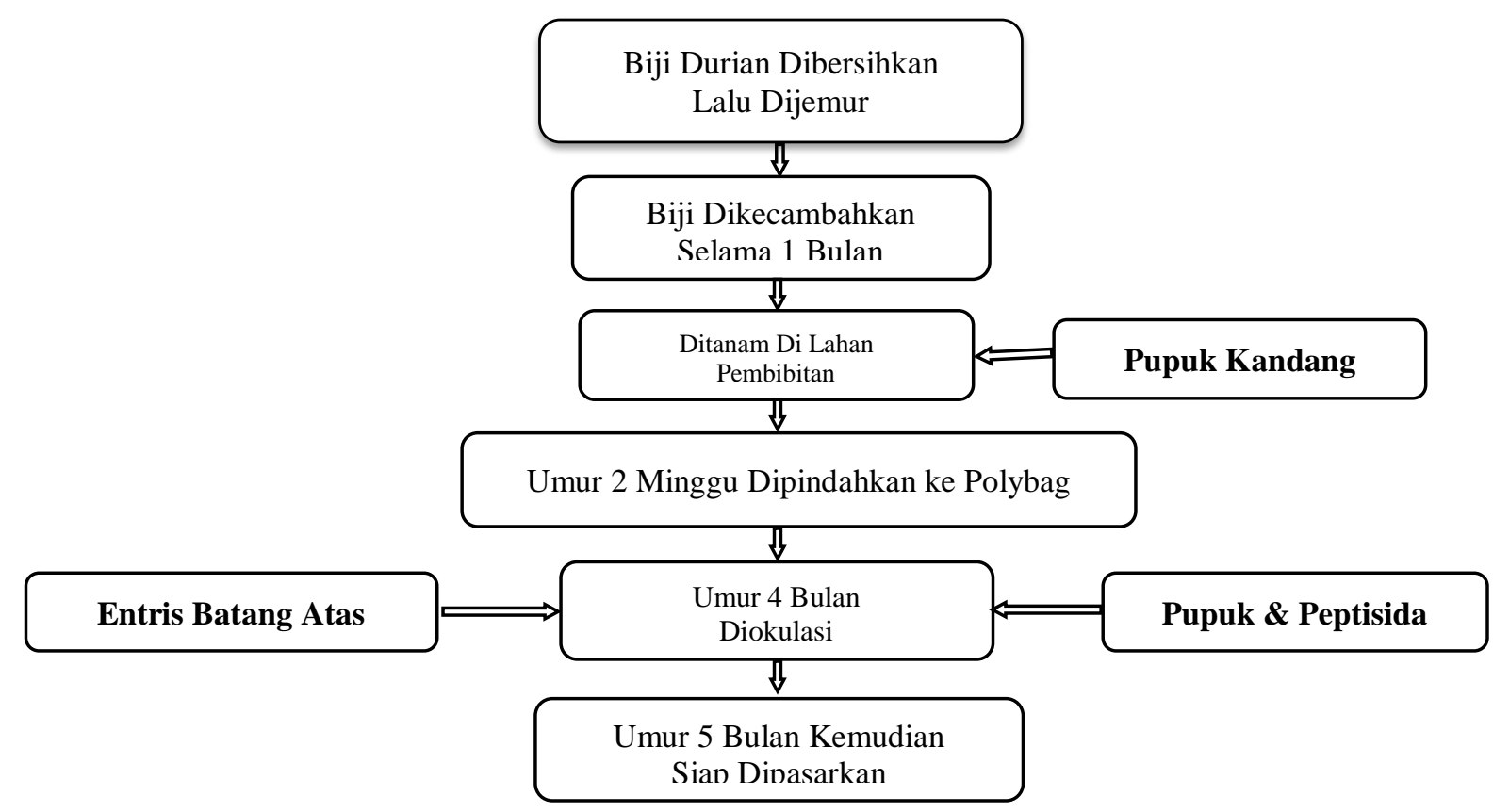

Gambar 2. Diagram alir pembibitan durian unggul lokal Palopo 
Caradde: Jurnal Pengabdian Kepada Masyarakat

Vol 1 No 2, Februari 2019

\section{HASIL DAN PEMBAHASAN}

\section{Pengelolan dan Produksi Pembibitan Durian Lokal}

Telah terbentuk unit usaha PPUPIK dan telah berjalan manajemennya berupa usaha pembibitan durian unggul lokal palopo, spanduk dan adanya kantor pemasaran (Gambar 3). Usahatani pembibitan durian lokal dilakukan dengan memperbanyak tanaman menggunakan teknik vegetatif (okulasi dan sambungan). Kegiatan diawali dengan persiapan lahan, pengadaan alat dan bahan, pembuatan naungan, pembuatan jaringan irigasi, penyiapan batang bawah dengan cara penyemaian biji durian, pemindahan bibit durian dari tempat penyemaian ke polibag, pemeliharaan (penyiangan, pemupukan, penggantiaan media tanam setelah di okulasi, pemangkasan) dan pemasaran (Tabel 1).
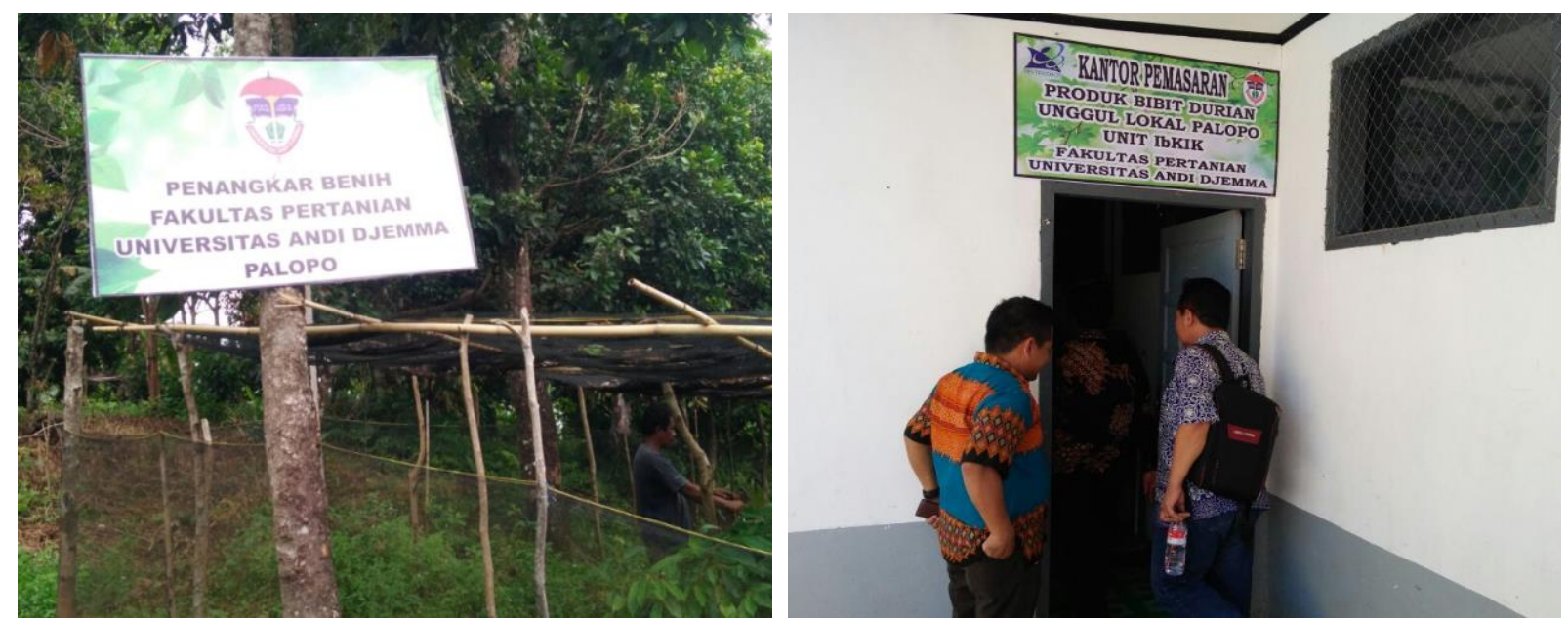

Gambar 3. Lokasi Produksi dan Kantor Pemasaran Bibit Durian Unggul Lokal Palopo

Tabel 1. Proses kegiatan pembibitan durian lokal Palopo mulai penyiapan benih sampai pemasaran selama 1 tahun

\begin{tabular}{|c|c|}
\hline Waktu (Bulan) & Kegiatan \\
\hline Januari & $\begin{array}{l}\text { Persiapan lahan (pembersihan, pembuatan bedengan, pemupukan), } \\
\text { penyediaan entris bawah (pembelian benih durian) }\end{array}$ \\
\hline Februari & $\begin{array}{l}\text { Persemaian benih durian untuk entris bawah (biji durian sudah diseleksi), } \\
\text { pengisian media tanam pada polibag }(15 \times 20 \mathrm{~cm})\end{array}$ \\
\hline Maret & Pemindahan bibit dari persemaian ke polibag $(15 \times 20 \mathrm{~cm})$ \\
\hline April & Penyediaan bahan dan alat okulasi (plastik, entris atas), melakukan okulasi \\
\hline Mei & $\begin{array}{l}\text { Melakukan okulasi, pemeliharaan (penyiraman, penyiangan, } \\
\text { pemberantasan hama dan penyakit) }\end{array}$ \\
\hline Juni & $\begin{array}{l}\text { Membuka okulasi, pemeliharaan (penyiraman dengan selang atau gembor } \\
\text { pada pagi dan sore hari jika tidak hujan) }\end{array}$ \\
\hline Juli & $\begin{array}{l}\text { Membuka okulasi, pengisian media tanam pada polibag ukuran } 20 \times 30 \mathrm{~cm} \\
\text { dan } 30 \times 40 \mathrm{~cm}\end{array}$ \\
\hline Agustus & $\begin{array}{l}\text { Penggantian polibag dari ukuran } 15 \times 20 \mathrm{~cm} \text { ke ukuran } 20 \times 30 \mathrm{~cm} \text { atau } 30 \\
\text { x } 40 \mathrm{~cm} \text {, tergantung permintaan pasar }\end{array}$ \\
\hline September & Pemeliharaan setelah pengantian media tanam (polibag) \\
\hline Oktober & Pemeliharaan, seleksi bibit (normal atau abnormal), pemasaran \\
\hline November & Pemeliharaan, pemasaran \\
\hline Desember & Pemasaran, persiapan lahan untuk produksi berikutnya \\
\hline
\end{tabular}


Waktu yang paling tepat untuk menanaman atau menyemai bibit durian yaitu awal musim hujan atau pada bulan Desember dan Januari. Penanaman dilakukan pada pagi atau sore hari untuk menghindari transpirasi yang terlalu tinggi. Pemeliharan berupa penyiangan atau pembersihan gulma dilakukan setiap bulan. Pertumbuhan gulma dapat menyebabkan kompetisi unsur hara dengan tanaman pokok. Jika dibiarkan akan menghambat pertumbuhan bibit durian. Selain itu, gulma bisa menjadi tanam inang bagi hama atau penyakit yang ada di persemaian (Cahyono, 2011; Sobir dan Napitupulu, 2015).

Pemupukan dilakukan selama pertumbuhan biji durian sampai entris batang bawah siap di okulasi. Pemupukan diberikan tiga minggu sekali pada bibit durian yang sudah dipindahkan dari pesemain ke polibag, gunanya merangsang pertumbuhan vegetatif. Pupuk yang digunakan yaitu pupuk daun organik dan NPK mutiara diberikan sebanyak 10 butir per polibag setiap bulan. Selama proses penyembuhan luka bibit (okulasi) tidak dilakukan pemupukan. Namun, setelah proses penyembuhan luka berakhir (ditandai dengan berhasilnya okulasi) dilakukan kembali pemupukan seperti pada tahap awal.
Penempelan atau okulasi (budding) adalah penggabungan dua bagian tanaman yang berlainan sedemikian rupa sehingga merupakan satu kesatuan yang utuh dan tumbuh sebagai satu tanaman setelah terjadi regenerasi jaringan pada bekas luka sambungan atau tautannya. Bagian bawah (yang mempunyai perakaran) yang menerima sambungan disebut batang bawah (rootstock atau understock) atau sering disebut stock. Bagian tanaman yang ditempelkan atau disebut batang atas, entres (scion) dan merupakan potongan satu mata tunas (entres) (Nasaruddin dan Nurfaeda, 2013; Gunawan, 2014).

Okulasi dilakukan saat batang bawah berdiameter 3-5 mm (sebesar pangkal lidi). Kriteria batang bawah dan batang atas dapat dilhat pada Tabel 2. Okulasi dilaksanakan pagi hari yaitu antara pukul 07.00-11.00 wita. Waktu tersebut tanaman sedang aktif berfotosintesis sehingga kambium tanaman juga dalam kondisi aktif dan optimum. Jika okulasi dilaksanakan di atas pukul 12.00 maka daun mulai layu akibat laju transpirasi yang tinggi. Namun, hal tersebut dapat dihindari jika okulasi dilakukan pada tempat yang ternaungi atau terhindar dari sinar matahari langsung.

Tabel 2. Kriteria batang bawah dan batang atas yang digunakan pada okulasi pembibitan durian unggul lokal Palopo

\section{Kriteria Batang Bawah}

Menggunakan biji asalan atau "sapuan". Berdiameter 3-5 $\mathrm{mm}$, berumur 3-4 bulan. Tingkat kesuburannya baik, perkembangan kambium dan fase pertumbuhannya aktif sehingga memudahkan pengupasan dan proses merekatnya mata tempel (entris) ke batang bawah.

Menggunakan polibag $15 \times 20 \mathrm{~cm}$ (umur bibit 1 bulan atau siap okulasi sampai umur 2 setelah okulasi). Setelah itu polibag diganti dengan ukuran $20 \times 30 \mathrm{~cm}$ atau $30 \times$ $40 \mathrm{~cm}$ tergantung permintaan pasar (konsumen). Seterusnya, semakin besar bibit durian maka semakin besar ukuran polibag yang digunakan. Kecuali, jika jarak pengangkutan jauh (efisiensi) maka polibag yang digunakan lebih kecil biasanya.

Komposisi media tanam subur, perbandingan $1: 1: 1$ (tanah top soil : pupuk kandang : sekam padi). Penyiraman dilakukan cukup (media cukup basah). Batang bawah dipupuk dengan NPK mutiara (1-2 minggu sebelum okulasi).

\section{Kriteria Batang Atas}

Batang atas (entres) yang digunakan memiliki cabang yang tidak terlalu tua dan juga tidak terlalu muda (setengah berkayu). Warna kulitnya coklat muda kehijauan atau abu-abu muda. Diameter cabang harus sebanding dengan besarnya batang bawah.

Cabang entres sudah tidak berdaun (daunnya sudah rontok). Jika cabang entres berdaun maka dilakukan perompesan daun (dua minggu sebelum pengambilan cabang entres). Pemupukan pohon induk dilakukan tiga minggu sebelum pengambilan entres untuk menjaga keseburan (kesehatan) pohon induk dan menghindari tertularnya penyakit sistemik pada bibit.

Entres diambil saat kulit kayu pada cabang mudah dikelupas dan kambiumnya aktif (kulit kayu akan tampak berair). Hal tersebut mempercepat proses pertautan antara entres dengan batang bawah. 
Proses perpindahan bibit durian ke polibag lebih besar dilakukan dua hingga empat bulan setelah okulasi dilakukan. Tujuannya agar bibit durian tumbuh dengan normal dan lebih cepat. Pertumbuhan yang cepat didukung peningkatan ukuran batang dan volume akar. Karena itu, akar memelukan media tumbuh yang lebih besar.

Pemangkasan dilakukan dengan memperhatikan pertumbuhan bibit durian. Memangkas ranting yang pertumbuhannya tidak diinginkan atau terserang penyakit. Bibit durian dipangkas dengan membuang tunas liar yaitu tunas yang berada di bawah tunas hasil okulasi.

Serangan hama pada pembibitan durian ditemukan kerusakan pada bagian tanaman dengan cara mengigit, melubangi, dan memakan daun terutama daun muda. Jenis hama yang biasa ditemukan yaitu ulat grayak dan kutu daun. Warna kloninya beragam seperti hijau, hitam, coklat, dan kuning. Kutu daun menyerang dengan cara bergorombol, mengisap cairan pada bagian bibit dan mengeluarkan cairan yang disukai oleh semut.

\section{Pemasaran Pembibitan Durian}

Pemasaran bibit durian unggul lokal Palopo tidak ditemukan kendala, karena didukung oleh promosi. Hal ini dikarenakan pembeli biasanya datang sendiri ke petani atau meminta bantuan kepada Dinas Pertanian untuk mencarikan penangkar bibit tanaman buah. Pemasaran bibit tanaman buah dilakukan melalui dua cara, yaitu penjualan secara langsung ke konsumen (perorangan) dan penjualan melalui pedagang (perantara, pengecer). Penjualan sebagian besar melalui pedagang (perantara, pengecer) dan hanya sebagian kecil saja yang dijual secara langsung ke konsumen. Penjualan secara langsung ke konsumen dilakukan penangkar dari showroom. Sistem pembayaran dilakukan secara kontan atau cicilan tergantung dari kesepakatan. Namun umumnya penangkar menggunakan sistem pembayaran tunai.
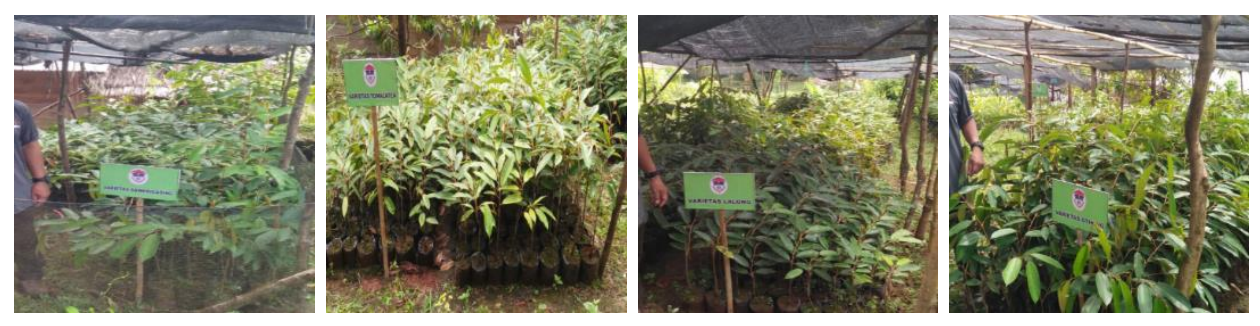

Gambar 4. Varietas dDurian yang tersedia di Unit Usaha PPUPIK Fakultas Pertanian Unanda Palopo

\section{Analisis Finansial}

Usaha yang dijalankan merupakan unit usaha Fakultas Pertanian Universitas Andi Djemma Palopo sehingga tidak ada biaya investasi yang dikeluarkan untuk menyewa tempat usaha, karena lahan milik Universitas.

Total produksi/bulan (bibit) $=2.567$, total produksi $/$ minggu (bibit) $=641,75$, operational usaha/bulan (hari) $=10$, total produksi $/$ bulan (bibit) $641,75 \times 10=6.418$, discount rate $(\%)=$ 13, dan pajak penghasilan $(\%)=5$. Perhitungan harga pokok produksi yang dijadikan asumsi, diantaranya NPV, Gross B/C, Net B/C, dan IRR. Berdasarkan hasil perhitungan harga pokok produksi bibit durian unggul lokal Palopo diperolah $\mathrm{Rp}$ $2.515,82$. Hasil kelayakan usaha pembibitan durian unggul lokal Palopo diperoleh nilai $\mathrm{NPV}=\mathrm{Rp} 1.345 .334,21$, gross $\mathrm{B} / \mathrm{C}=1.7244$, net $\mathrm{B} / \mathrm{C}=3.9214$, dan $\mathrm{IRR}=63 \%$. Perhitungan kriteria kelayakan usaha disajikan melalui arus kas (cash flow). Nilainilai tersebut menyatakan bahwa usaha pembibitan durian unggul lokal Palopo layak untuk dilakukan. Selain itu, terdapat juga nilai pay back period (PBP) untuk usaha tersebut selama 4.3822 bulan. Pay back period (PBP) adalah teknik penilaian terhadap jangka waktu (periode) pengembalian investasi suatu proyek atau usaha. Perhitungan dapat dinilai dari perhitungan kas bersih yang diperoleh setiap tahun. Bisnis yang pay back period-nya cepat atau singkat, pengembaliannya kemungkinan besar akan 
dipilih. Namun, secara normatif tidak ada pedoman yang biasa dipakai untuk menentukan pay back maksimum (Nurmalina et al., 2009; Suratiyah, 2015).

Penentuan layak tidaknya suatu investasi ditinjau dari aspek keuangan, maka dapat digunakan beberapa kriteria. Setiap penilaian layak perlu diberikan nilai yang standar untuk usaha yang sejenis dengan cara membandingkan dengan rata-rata industri atau target yang telah ditentukan (Budiono, 1992; Soekartawi, 2010). Suatu bisnis dinyatakan layak apabila jumlah seluruh manfaat yang diterima lebih besar dibandingkan dengan biaya yang dikeluarkan. Selisih antara manfaat dan biaya adalah manfaat bersih atau arus kas bersih. Suatu bisnis dikategorikan atau dinyatakan layak apabila nilai NPV lebih besar dari 0 (NPV > $0)$ yang artinya bisnis tersebut menguntungkan atau dapat memberikan manfaat, begitu pula sebaliknya apabila nilai NPV lebih kecil dari $0(\mathrm{NPV}<0)$ maka bisnis tersebut tidak layak untuk dijalankan (Nurmalina et al., 2009; Suratiyah, 2015).

Gross B/C merupakan kriteria kelayakan usaha lainnya yang biasa digunakan dalam analisis bisnis. Manfaat ataupun biaya merupakan nilai kotor (gross) sehingga kriteria gross B/C dapat lebih menggambarkan bahwa adanya pengaruh tambahan biaya terhadap tambahan manfaat yang diterima oleh produsen. Apabila gross B/C $>1$, maka bisnis yang dijalani dinyatakan layak untuk dijalani (Nurmalina et al., 2009; Suratiyah, 2015). Usaha minuman jahe merah instan pun memiliki nilai gross B/C lebih besar dari 1 yang dinyatakan bahwa usah tersebut layak dijalankan. Net B/C ratio adalah ratio antara manfaat bersih yang bernilai positif dengan manfaat bersih yang bernilai negatif. Hal ini berarti bahwa manfaat bersih yang menguntungkan bisnis yang dihasilkan terhadap satu satuan kerugian dari bisnis tersebut. Menurut Nurmalina et al., (2009), suatu bisnis dinyatakan layak apabila nilai net B/C lebih besar dari 1 dan dikatakan tidak layak apabila nilai net B/C lebih kecil dari 1 . Usaha minuman jahe merah instan memiliki nilai net B/C lebih besar dari 1 dan dinyatakan layak untuk dijalankan.

Kelayakan bisnis pun dapat dinilai dari seberapa besar pengembalian bisnis terhadap investasi yang ditanamkan. Hal ini dapat ditunjukkan dari nilai internal rate of return (IRR). IRR merupakan tingkat discount rate (DR) yang menghasilkan NPV sama dengan nol. Sebuah bisnis dinyatakan layak apabila nilai IRR lebih besar dari opportunity of cost (DR) (Nurmalina et al., 2009; Sumarjono, 2000). Usaha pembuatan minuman jahe merah instan dinyatakan layak karena nilai IRR $63 \%$ lebih besar dibandingkan dengan nilai DR $13 \%$ yang berarti usaha tersebut layak untuk dijalankan.

\section{SIMPULAN DAN SARAN}

Pada awalnya, pembibitan durian unggul lokal Palopo yang dimiliki Fakultas Pertanian Universitas Andi Djemma Palopo belum memiliki standar baku okulasi dan belum tersedia fasilitas yang memadai. Namun setelah pendampingan, akhirnya didapatkan formula standar untuk okulasi, perbaikan fasilitas, dan perbaikan teknik pembibitan. Berdasarkan analisis kelayakan usaha yang dilakukan, usaha pembibitan durian unggul lokal Palopo dinyatakan layak karena nilai IRR $63 \%$ lebih besar dibandingkan nilai DR 13.\%. Disarankan menggunakan etris atas yang bersertifikasi dari Departemen Pertanian.

\section{UCAPAN TERIMA KASIH}

Ucapan terima kasih kepada Kementrian Ristekdikti untuk pendanaan kegiatan ini melalui Hibah DRPM Pengabdian PPUPIK Tahun Anggaran 2018.

\section{DAFTAR RUJUKAN}

Belgis $\mathrm{M}$, Wijaya $\mathrm{CH}$, Apriyantono A, Kusbiantoro B, Yuliana ND, 2017. Volatiles and aroma characterization of several lai (Durio kutejensis)and durian (Durio zibethinus) cultivars grown in Indonesia. Sci. Horticulturae, 220 : 291298

Budiono B, 1992. Industri Kecil dalam Perspektif Budaya. Surabaya, Seminar Prospek Industri Kecil Dalam Perkembangan Perekonomian Indonesia.

Cahyono B, 2011. Cara Sukses Berkebun Durian Impor \& Lokal. Pustaka Ilmu. Jakarta. 
Gunawan E, 2014. Perbanyakan Tanaman: Cara Praktis dan Populer (Cangkok, Setek, Okulasi, Sambung dan Biji). AgroMedia Pustaka. Jakarta.

Gorinstein S, Poovarodom S, Leontowicz H, Leontowicz M, Namiesnik J, Vearasilp S, 2011. Antioxidant properties and bioactive constituents of some rare exotic Thai fruits and comparison with conventional fruits in vitro and in vivo studies. Food Research International, 44 : 2222-2232

Nasaruddin dan Nurfaeda, 2013. Mencangkok, Okulasi, dan Menyambung. Masagena Press.
Nurmalina N, Sarianti T, Karyadi A. 2009. Studi Kelayakan Bisnis. Institut Pertanian Bogor, Bogor.

Sobir dan Napitupulu RM, 2015. Berkebun Durian Unggul. Penebar Swadaya. Jakarta.

Soekartawi, 2010. Analisis Usaha Tani. UI Press. Jakarta.

Sumarjono, 2000. Teori Ekonomi Produksi.Raja Grafindo Perseda, Jakarta.

Suratiyah K, 2015. Ilmu Usaha Tani (Edisi Revisi). Penebar Swadaya. Jakarta.

Wiryanta BTW, 2001. Bertanam Durian. Agromedia, Jakarta 